\title{
Light regimen-induced variability of photosynthetic pigments and UV-B absorbing compounds in Luzula sylvatica from Arcto- Alpine tundra
}

\author{
Miloš Barták $^{1 *}$, Alla Orekhova ${ }^{1}$, Jakub Nezval ${ }^{2}$, Michal Oravec ${ }^{3}$, Josef \\ Hájek $^{1}$, Vladimír Špunda ${ }^{2}$, Jan Tř́íska ${ }^{3}$, Michaela Bednaříková ${ }^{1}$, Gabriella \\ Nora Maria Giudici ${ }^{4}$, Radek Pech ${ }^{2}$ \\ ${ }^{1}$ Masaryk University, Department of Experimental Biology, Laboratory of Photosynthetic \\ Processes, Kamenice 5, 62500 Brno, Czech Republic \\ ${ }^{2}$ University of Ostrava, Faculty of Science, Departmment of Physics, Chittusiho 10, \\ Slezská Ostrava, Czech Republic \\ ${ }^{3}$ Global Change Research Institute, Czech Academy of Science, Bělidla 4a, 60300 Brno, \\ Czech Republic \\ ${ }^{4}$ University of Naples Federico II, Department of Agriculture, 80055 Portici, Italy
}

\begin{abstract}
The aim of this study was to evaluate the effects of different in situ light regimen on ecophysiological parameters of Luzula sylvatica leaves. Plants of L. sylvatica grown under natural sunny and shade conditions in Arcto-Alpine tundra were analyzed with respect to their leaf anatomy, content of photosynthetic pigments, UV absorbing compounds and phenanthrenoid compounds. Relationship between chlorophyll concentrations $\left(\mathrm{Chl}_{\mathrm{a}+\mathrm{b}}\right)$ and SPAD values was determined for sun and shade leaves measured repeatedly within summer and autumn seasons 2019 and 2020. Pooled data showed curvilinear $\mathrm{Chl}_{\mathrm{a}+\mathrm{b}}$ to SPAD relationship with the highest $\mathrm{Chl}_{\mathrm{a}+\mathrm{b}}$ and SPAD values found for shade leaves. Sun leaves had higher UV-B absorbing compounds contents than shade ones. The HPLC-DAD analysis revealed significant amount of soluble flavonoids in Luzula sylvatica leaves, amongst others the flavone-luteolin and its derivatives (e.g. tentatively identified luteolin-methyl-glucoside and luteolin-glucoside). The accumulation of luteolin based compounds in sun acclimated leaves is also plausible explanation for the higher antioxidant activity determined in sun leaf extraxts. Such response of flavonoid metabolism may help L.S. to cope with excessive-light stress through UVattenuation mechanism and ROS scavanging. Additionally, phenanthrenoid compounds contents in L. sylvatica leaves were determined. Altogether, 9 phenanthrenoid compounds were identified by HPLC-HRMS. Their content was markedly different (up to the factor of 5) between sun and shade leaves of L.sylvatica.
\end{abstract}

DOI: $10.5817 / \mathrm{CPR} 2020-2-20$

\footnotetext{
Received October 6, 2020, accepted December 30, 2020.

*Corresponding author: M. Barták <mbartak@sci.muni.cz>

Acknowledgements: The study was supported by the ECOPOLARIS project (CZ.02.1.01/0.0/0.0/ 16_013/0001708) provided by the Czech Ministry of Education, Youth, and Sports. The authors would like to express their thanks to the CzechPolar2 (LM2015078) for the ability to use laboratory infrastructure that enabled microscopy analysis. The authors from the Masaryk University are indebted to the ARCTOS MU project for support. The authors from CzechGlobe thank the Ministry of Education, Youth and Sports of CR, project SustES - Adaptation strategies for sustainable ecosystem services and food security under adverse environmental conditions (CZ.02.1.01/0.0/0.0/16_019/0000797).
} 
Key words: Juncaceae, SPAD values, chlorophyll, carotenoids, phenanthrenoids, sun leaves, shade leaves

List of symbols and abbreviations: Car - carotenoids, Chl - chlorophyll, Chl $\mathrm{a}_{\mathrm{a}+\mathrm{b}}-$ total chlorophyll content, HPLC-DAD - high performance liquid chromatography-diode array detection, HPLC-HRMS - high performance liquid chromatography-high resolution mass spectrometry, L.W. - lyophylised weights, SPAD - Soil Plant Analysis Development

\section{Introduction}

Within the last decades, several comparative studies focused on the leaf structure and ecophysiological functioning have demonstrated that the majority of vascular plants species possess the ability to develop anatomically distinct leaves in response to different light regimen (e.g. Terashima et al. 2001, Mathur et al. 2018). Different light intensity available for plants in their natural habitats promotes alterations in the structural organization of the leaves, resulting in leaves of sun and shade types. Incident light is, therefore, an environmental variable, influencing the formation of plant phenotypes. High and/or low light induces the process of leaf acclimation to different light levels. The changes comprise the differences in leaf thickness, leaf mass per unit area, thickness of palisade and spongy parenchyma, photosynthetic pigment contents and photosynthetic performance. Sun leaves have higher photosynthetic capacity, i.e. light-saturated rate of net photosynthesis on a leaf area basis (e.g. Huang et al. 2014), and higher nitrogen content than shade leaves (e.g. Pandey and Kushwaha 2005). Among these parameters, differences in chlorophyll contents have high indicative values, since they respond sensitively to the changes in light environment and are easily determined both in laboratory and field studies.

Since the 90-ies, many studies have provided information about the relationships between chlorophyll contents in leaves and their spectral parameters (e.g. Markwell et al. 1995). Over the last dec- ades, various optical methods have been developed to assess leaf chlorophyll content nondestructively (see $e . g$. Dong et al. 2019). Those methods are based on the absorbance or reflectance measured at certain wavelengths on intact leaves. Recently, several chlorophyll meters exploit this measuring principle are used both in laboratory and field studies, particularly those focused on the effects of nitrogen supply to chlorophyll contents (Gáborčík 2003, Netto et al. 2005, Xiong et al. 2015). Hand-held chlorophyll meters measure leaf absorbance at two different wavelengths, in the spectral range of red and near-infrared. As an output, they calculate indexvalues that specify leaf chlorophyll content. In the domain of red light, strong chlorophyll absorption occurs and the nearinfrared light measurement is made to record differences in between the leaf structure. This method, when combined with the traditional wet chemical extraction methods, represents an efficient tool for plant ecophysiology (see e.g. Parry et al. 2014) since it may provide huge data sets for field studies focused on the effects of varying light environment on chlorophyll contents (Mielke et al. 2010).

In our study, we focused on ecophysiology of sun and shade leaves of Luzula sylvatica from Arcto-Alpine tundra. We measured SPAD (Soil Plant Analysis Development) value and, similarly to Uddling et al. (2007) related to chlorophyll content. Aditionally, the analysis of UV screening compounds was done. 


\section{Material and Methods}

\section{Species characteristics}

Luzula sylvatica (Huds.) Gaudin (Juncaceae) is an evergreen plant with round stems. Stems grow from a thick obliquely ascending rhizome, the leaves are bright green, glossy, and linear flat (Kirschner et al. 2002). Basal leaves grow widely spaced. They are about $20-30 \mathrm{~cm}$ long, at the base and $1.5 \mathrm{~cm}$ wide. The leaves are gradually tapering toward the leaf tip. Cotyledon leaves are much shorter. They grow in the number of four to six from closed sheaths without ears. The leaves are glossy, with white long hairs along the edges. The inflorescence of L. sylvatica is tall, sparse and spreading, often slightly overhanging, with flowers in few-numbered groups. Seeds are slightly shiny and with a small

\section{Site description (Tabulové skály rocks)}

Tabulové skály rocks $\left(50^{\circ} 5^{\prime} 15.398^{\prime \prime} \mathrm{N}\right.$, $\left.17^{\circ} 13^{\prime} 52.435^{\prime \prime E}\right)$ are the part of Natural Reserve Praděd (Jeseníky Mountains, Czech Republic). It is a natural forest-free area located above the tree line (1 $420 \mathrm{~m}$ a.s.1.), which has the character of peak rocks. They were formed by frost weathering processes, thus they represent typical rocky outgrowths affected by frost.

They are composed of phylonite rocks, with a high presence of small hollows (especially in the SW-facing walls) following the lines of phylonite shale (see Fig. 1). The hollows are inhabited by moss and lichen flora, as well as flat plate-shaped boulders. Tabulové skály rocks are, therefore, considered bryologically (Kučera et al. 2009) and lichenologically important locality. On these rocky outgrowths, the following vascular plants grow: Cardamine resedi folia, Sedum alpestre, Salix herbacea, Rhodiola rosea, Rhodiola rosea. The vegetation of the Tabulové skály rocks is classified as alpine plant communities represented by wind-swept alpine grass- flesh.

L. sylvatica is widespread mainly in higher elevations (mountains and foothills) in Europe, especially in its western and southern parts. It appears in Arcto-Alpine tundra as well. The species is also rarely found outside Europe, e.g. Asia Minor and the areas adjacent to the Caucasus. L. sylvatica is a frost-resistant perennial growing on continuously moist habitats that are partially shaded and have weakly acidic and humus soil. The species is typical shade tolerant with a high capacity to grow in forest understory of mountainous ecosystems thanks to the capability to perform photosynthesis at low light intensities (Holub et al. 2019).

lands (Juncion trifidi) and closed alpine grasslands (Nardo-Caricion rigidae) - Ziedler et al. $(2012,2018)$. In the surroundings of the rocky outgrowhs, patterned grounds are developed. They are classified as the Earth hummocks and non-sorted stripes (Křižek et al. 2019). The neighbourhood of the Tabulové skály rocks is affected by irregularly distributed scattered polycormones of non-native Pinus mugo, planted there mainly between 1874 and 1927 . Recently, the introduced $P$. mugo is established at the site and has capacity of reproduction through seedlings (Šenfelder and Treml 2020). Within the frame of ECOPOLARIS project (since 2017), lichen flora of the Tabulové skály rocks is studied in relation to microclimate, as well as L. sylvatica (Fig. 2). Since 2018, the air temperature and relative air humidity have been measured at the rock edge (Minikin, Environmetal Monitoring Systems, Czech Republic) as a part of the ECOPOLARIS project. Monthly means are presented in Fig. 3. 


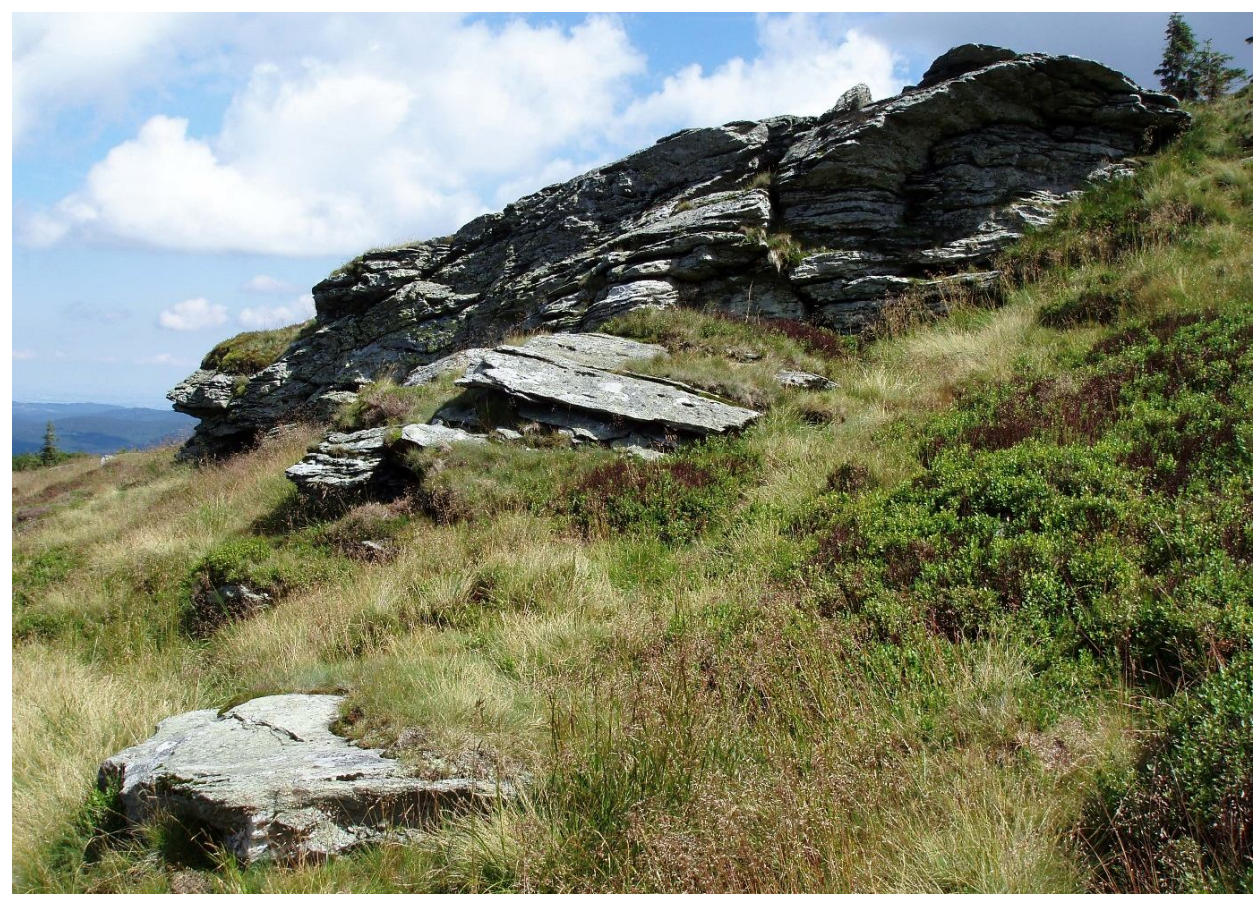

Fig. 1. Tabulové skály rocks are rocky outhgrowths located at alpine zone above the treeline at the altitude of $1430 \mathrm{~m}$ a.s.l. Vegetation cover is dominated by Arcto-Alpine species.

\section{Local microclimate}

The air temperature $5 \mathrm{~cm}$ above ground was measured by a Minikin (Environmental Monitoring Systems Brno, Czech Republic) datalogger equipped by a termocouple. The air temperature was measured at $1 \mathrm{~h}$ intervals, and monthly means were calculated. The sensor was located close to the rocky outgrowth to characterize the microclimate of the transition zone between lichen-dominated rock and Arcto-
Alpine grass stands. Other climatic characteristics, i.e. precipitation and relative air humidity $(\mathrm{RH})$ were taken from the open resources ([1] - Meteoblue). Additionally, heat fluxes from/to soil were measured in 2020 by HFP01 sensors (Hukseflux, Netherlands) linked to a datalogger micro$\log$ V3A (Environmental Monitoring Systems, Czech Republic).

\section{Anatomical characteristics of sun and shade leaves}

Cross sections of leaves growing in shade and on the sun habitats (Fig. 2) were made for anatomical analysis. They were observed under a digital light microscope (Keyence WHX-900, Japan). The following anatomical parameters were measured and evaluated: the thicknesses of whole leaf, the thickness of upper and lower epi- dermis, and length, width, and the area of parenchyma segments (on a cross section) without chloroplasts. The parameters were evaluated digitally using the Keyence software. All biometric data (at least 85 replicates per measured parameter) were processed in order to calculate means and standard deviations. 


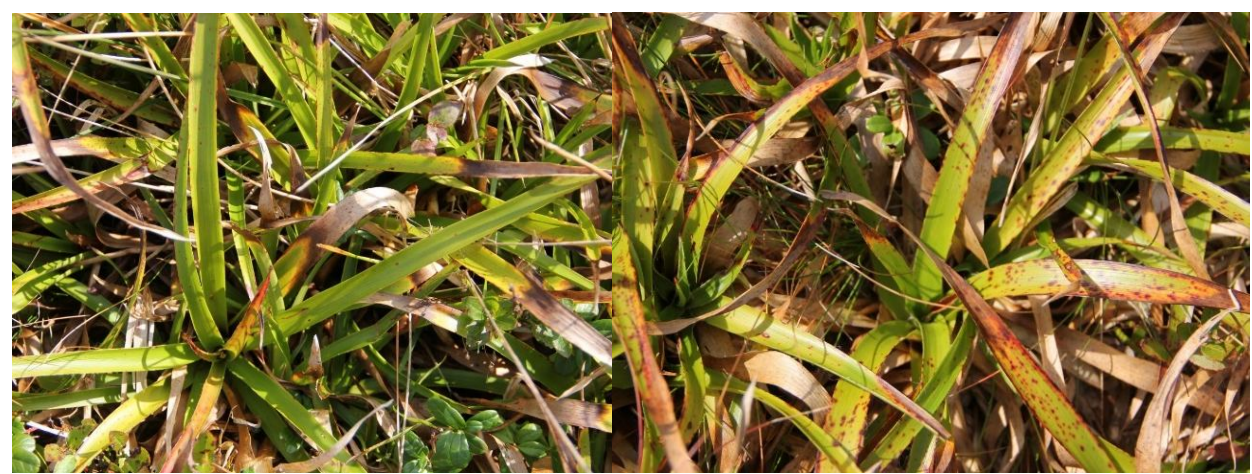

Fig. 2. Example of L. sylvatica plants from intermediate habitat located close to a place partly shaded by Pinus mugo (left, Spot 1) and sunny habitat close to the Tabulové skály rocks (right, Spot 2).

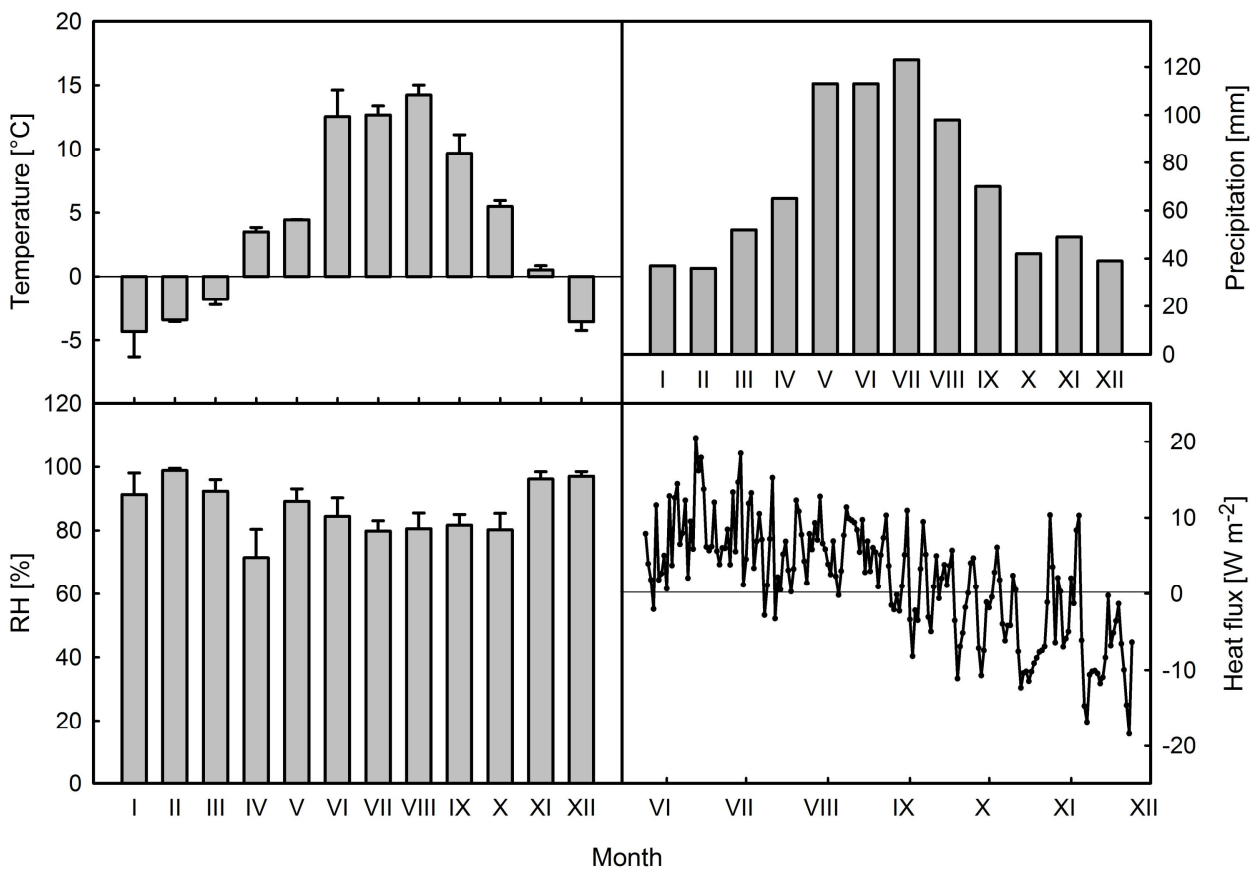

Fig. 3. Microclimate of the Tabulové skály Rocks (monthly mean air temperature measured $5 \mathrm{~cm}$ above rock surface, 2018-2020) by a Minikin datalogger (ECOPOLARIS project) - upper left. Monthly means of precipitation (upper right), and relative air humidity (lower left), Mothly means \pm standard deviations are presented. Source: [1] - Meteoblue (see Other sources in References). Lower right - daily means of heat flux to/from the soil (positive/negative values) in $\mathrm{W} \mathrm{m}^{-2}$ recorded in the depth of $5 \mathrm{~cm}$ in 2020 . 


\section{SPAD measurements}

Field measuremenst were conducted at several spots in the Natural Reserve Praděd located in the altitude of 1350 to $1430 \mathrm{~m}$ a.s.l. For the field masurements, polycormones of L. sylvatica from (1) open sunny habitats, (2) intermediate, and (3) shade ones (under the canopy of lowdensity forest close to the treeline) were chosen. Optical measurements of chlorophyll concentration on L. sylvatica leaves were taken by a SPAD 502 meter (Konica Minolta Sensing, Inc., Sakai, Osaka, Japan). It measured the leaf absorbance in red and near-infrared regions. The light was emit-

\section{Chlorophyll contents analysis}

Immediately after the field measurements with the SPAD-502 Plus (Konica Minolta, Inc.), each leaf was excised from the plant and a leaf part was taken with the measuring point in the middle of the leaf segment. The leaves were transferred to a laboratory in a portable thermoelectric fridge, and subseuently dried (1.0 mbar for $48 \mathrm{~h}$ ) in a lyophilizator (Heto, Maxi Dry Lyo Freeze-dryer, Gemini, Netherlands). After lyophilization, the samples were used for determination of pigment content. Chlorophyll Chl $a$, Chl $b$ and carotenoids (Car)

\section{Extraction of phenolics compounds}

Lyophilised middle leaf segments of L. sylvatica $(100 \pm 2 \mathrm{mg}$ of lyophilised weight, L.W.) were cut to small pieces and homogenized using a mortar and pestle (one segment per sample) in $3 \mathrm{ml}$ of methanol (HPLC grade, Merck, Germany). Homogenized samples were ultrasonicated at the laboratory temperature for $5 \mathrm{~min}$. (Ultrasonic compact cleaner UC 006 DM1, ted by two LEDs with peak wavelengths at $650 \mathrm{~nm}$ and $940 \mathrm{~nm}$. These LEDs emit light in sequence from the emitting window to a photodiode detector (when the measuring head is closed). The light passes through the leaf in the measuring head, and a certain amount transmits through the leaf. The transmitted light strikes the receptor and is converted into electrical signal. Then, the instrument calculates a SPAD value by division of light transmission intensities at $650 \mathrm{~nm}$ by $942 \mathrm{~nm}$. The SPAD value specifies the relative content of chlorophyll in the leaf.

were extracted with $96 \%$ ethanol following the method of Lichtenthaler and Wellburn (1983) using a Specord 205 (Analytik, Jena, Germany) spectrophotometer. The absorbance measured at $649 \mathrm{~nm}$ and $665 \mathrm{~nm}$ was used for Chl $b$ and Chl $a$, and $470 \mathrm{~nm}$ for Car evaluation. Additionally, spectral absorbance curves (190-800 $\mathrm{nm}$ ) were analyzed with a special attention to the constitutive amount of UV-B absorbing compounds (evaluated according to Newsham 2003), their proportion to total chlorophyll content, respectively.

Czech Republic) to increase extraction efficiency. Subsequently, extracts were centrifuged for $3 \mathrm{~min}$. at $6000 \mathrm{RPM}$ (EBA20, Hettich Zentrifugen, Germany). The supernatant was filtered through 0.2 um syringe filter into the amber vials and stored in the freezer $\left(-21^{\circ} \mathrm{C}\right)$ before the HPLC-DAD analysis and determination of antioxidant activity. 


\section{HPLC-DAD analysis of phenolic compounds}

The analysis of soluble phenolic compounds present in L. sylvatica leaves was performed on HPLC system Agilent 1200 (Agilent Technologies, USA) equipped with the Hypersil GOLD chromatographic column $(\mathrm{C} 18,50 \times 2.1 \mathrm{~mm}, 1.9 \mu \mathrm{m}$; Thermo Scientific, USA). The column compartment was heated to $30^{\circ} \mathrm{C}$. Acetonitrile-water solutions were used as mobile phases (mobile phase A: $5 \%$ acetonitrile, B: $80 \%$ acetonitrile). Both mobile phases were acidified using the formic acid (999:1, v/v).
The flow rate of mobile phases was constant during whole separation process $\left(0.3 \mathrm{ml} \cdot \mathrm{min}^{-1}\right)$, the gradient is described in detail in Table 1. The injection volume of leaf extracts was set to $5 \mu$ l. Optical chromatograms were recorded at 270,314, 360, $535 \mathrm{~nm}$, and absorption spectra were collected in the range from 220 to $750 \mathrm{~nm}$. For the relative quantification of phenolic compounds in plant material peak areas detected at $360 \mathrm{~nm}$ were used (adjusted to L.W. and extract volume of samples).

\begin{tabular}{ccc}
\hline Time [min.] & Mobile phase A [\%] & Mobile phase B [\%] \\
\hline 0.0 & 100 & 0 \\
2.0 & 95 & 5 \\
5.0 & 92 & 8 \\
8.0 & 90 & 10 \\
12.0 & 85 & 15 \\
13.5 & 85 & 15 \\
17.0 & 65 & 35 \\
19.0 & 20 & 80 \\
21.5 & 0 & 100 \\
24.0 & 0 & 100 \\
24.5 & 100 & 0 \\
31.0 & 100 & 0 \\
\hline
\end{tabular}

Table 1. The gradient of mobile phases used for the HPLC separation of soluble phenolic compounds present in Luzula sylvatica leaves.

\section{Determination of antioxidant activity}

The antioxidant activity of Luzula sylvatica leaf extracts (containing soluble phenolic compounds) was determined using the 2,2-diphenyl-1-picryl-hydrazyl stable radical (DPPH•, Sigma-Aldrich, Germany). This colorimetric assay was performed on UV-VIS double beam absorption spectrophotometer Specord 250 (Analytik Jena, Germany). Method is based on the measurement of the absorbance difference between DPPH solution (blank) and $\mathrm{DPPH} \bullet$ solution with added extract containing antioxidants. The absorbance is recorded at $515 \mathrm{~nm}$ where radical form of
DPPH exhibits local absorption maximum. $\mathrm{DPPH} \bullet$ is reduced after the interaction with antioxidants and the absorbance at $515 \mathrm{~nm}$ decreases proportionally to the content and antioxidant activity of compounds in tested sample, since reduced form of DPPH is not absorbing at $515 \mathrm{~nm}$. For the determination of antioxidant activity, leaf extracts were prepared using the same procedure as mentioned for HPLC analysis of phenolic compounds. However, these extracts were diluted before the measurement (1:4, extract:methanol, v/v). DPPH• solution was prepared by dissolving a $0.0075 \mathrm{~g}$ 
of the substance in $100 \mathrm{ml}$ of methanol. Trolox (6-hydroxy 2,5,7,8-tetramethylchroman 2-dicarboxylic acid, Sigma Aldrich, Germany), a widely used standard antioxidant (vitamin E derivative), was used for the calibration. Calibration regression was established by preparing the Trolox concentration series of $0,25,50,100,200$ and $300 \mu \mathrm{M}$. $2.0 \mathrm{ml}$ of DPPH solution were poured to the 6030-UV quartz cuvette (Hellma, Germany) and $0.5 \mathrm{ml}$ of methanol (in case of blank), $0.5 \mathrm{ml}$ of diluted extract (in case of sample) or $0.5 \mathrm{ml}$ of Trolox (calibration solution) were added. Samples were shaken and kept in dark for $10 \mathrm{~min}$. at laboratory temperature, subsequently, the absorbance was measured at $515 \mathrm{~nm}$ (monochromator optical slit width was set to $0.5 \mathrm{~nm}$ ). The resulting values were expressed in Trolox equivalent antioxidant capacity (TEAC) units. Finally, the TEAC values were adjusted to sample L.W.

\section{Evaluation of phenanthrenoid compounds by (HPLC-HRMS)}

Leaf samples were, after lyophilisation, kept at $-80^{\circ} \mathrm{C}$ until further investigation. Dry weight of $100 \mathrm{mg}$ of the samples were homogenized using a mortar and pestle with the addition of liquid nitrogen and then extracted using a methanol:chloroform: $\mathrm{H}_{2} \mathrm{O}$ solution (1:2:2). An aliquot of the upper (polar) phase was used to analyse saccharides, phenolic compounds, amino acids, and Krebs cycle acids employing an UltiMate 3000 high performance liquid chromatograph coupled with an LTQ Orbitrap XL high resolution mass spectrometer (HRMS) (Thermo Fisher Scientific, Waltham, MA, USA).

A Hypersil GOLD column $(150 \times 2.1$ $\mathrm{mm}, 3 \mu \mathrm{m}$; Thermo Fisher Scientific) was used for the separation. The flow rate of the mobile phase was $0.3 \mathrm{ml} \cdot \mathrm{min}^{-1}$ and column temperature was set to $30^{\circ} \mathrm{C}$. The mobile phase (A) consisted of acetonitrile and (B) of water containing $0.1 \%$ acetic acid. Both mobile phases (A) and (B) were filtrated and degassed for $10 \mathrm{~min}$. in an ultrasonic bath prior to use. Gradient elution chromatography started with $10 \%$ acetonitrile (A) and $90 \%$ water ( $0.1 \%$ acetic acid) (B) and was held for $5 \mathrm{~min}$. Within the time interval of 5-20 min., the mobile phase (A) composition was increased to $90 \%$. This composition was then maintained for 5 min., after which the system was over a period of $5 \mathrm{~min}$. equilibrated to initial conditions (10\% acetonitrile (A) and $90 \%$ water $(0.1 \%$ acetic acid $))$. The wavelengths 254, 272, 274, and $331 \mathrm{~nm}$ were monitored.

The HRMS was equipped with a HESI II heated electrospray ionization source (Thermo Fisher Scientific) and was operated in full scan mode with resolution of 60000. Full scan spectra were acquired over mass range $50-1000 \mathrm{~m} / \mathrm{z}$ in positive polarity mode and $65-1000 \mathrm{~m} / \mathrm{z}$ in negative polarity mode. The resolution and sensitivity of the HRMS were regularly controlled by injecting a mixture of phenolic compounds. As a control, phthalate was taken as a lock mass. The compounds were assigned on the basis of our own mass library created using standards measured in MS and MSn modes.

For analyses, the following chemicals were used. Chloroform HPLC grade for extraction was obtained from Fisher Chemical (Waltham, MA USA). Methanol for extraction was obtained from VWR chemicals (Radnor, Pensylvánie, USA). Acetonitrile hypergrade for LC-MS LiChrosolv ${ }^{R}$ was supplied by Merck KGaA (Darmstadt, Germany). Acetic acid was obtained from Sigma-Aldrich Chemie GmbH (Steinheim, Germany). The Purelab Classic (ELGA LabWater, High Wycombe, Bucks, UK) was used to generate high purity water for preparation of aqueous mobile phase. 


\section{Results and Discussion}

\section{Leaf anatomy}

Anatomical characteristics differed between sun and shade leaves of L. sylvatica from sunny and shade habitats. The sun leaves were thicker, having thicker upper and lower epidermis as well. Dimension of the sections of parenchymatic cells with no chlorophyll was larger in sun than shade leaves. However, the parenchymatic cell section was longer in shade than sun leaves (see Fig. 4). Chlorophyll-containing cells were located between the epidermis and parenchymatic cells both in sun and shade leaves. However, density of chlorophyll-containing cells was higher in shade than sun leaves. This was supported by analysis of chlorophyll contents: it was much higher in shade than sun leaves (see Table 2).
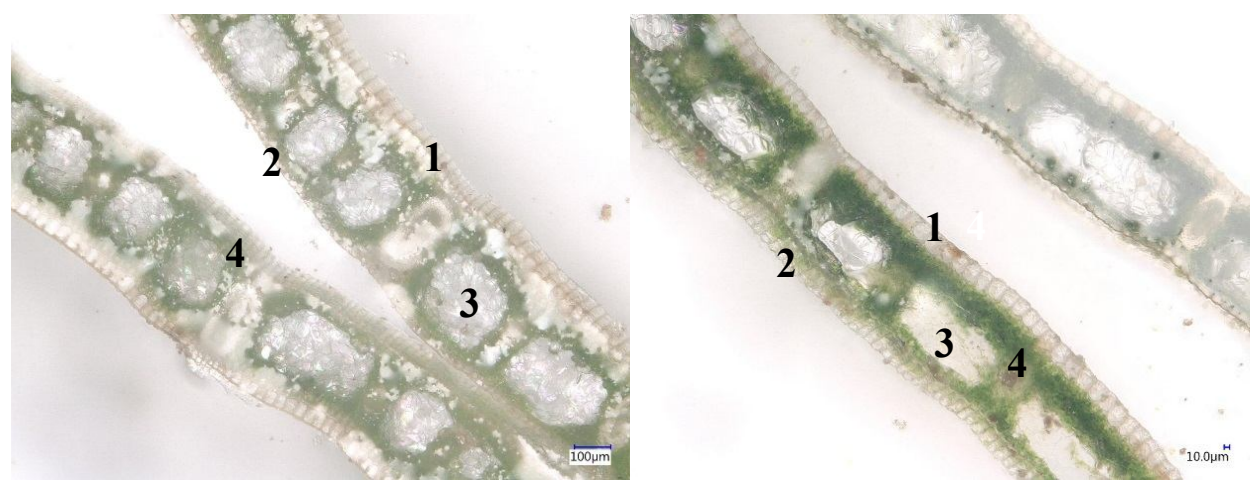

Fig. 4. Cross section of typical sun (left), and shade leaf (right) with distinguished anatomical stuctures: upper (1) and lower (2) epidermis, large space filled with chlorophyll-free parenchyma cells (3), and chlorophyll-containing cells (4).

\begin{tabular}{|l|cc|cc|}
\hline \multirow{2}{*}{ Anatomical structure } & \multicolumn{2}{c|}{ Sun leaves $[\mu \mathrm{m}]$} & \multicolumn{2}{c|}{ Shade levas $[\mu \mathrm{m}]$} \\
\cline { 2 - 5 } & average & SD & average & SD \\
\hline Leaf thickness & 342.87 & 27.32 & 224.85 & 14.40 \\
Upper epidermis & 40.90 & 8.93 & 32.29 & 4.88 \\
Lower epidermis & 23.06 & 6.18 & 18.22 & 3.95 \\
Parenchyma area $\left[\mu \mathrm{m}^{2}\right]$ & 30496.14 & 9996.30 & 26299.42 & 8165.23 \\
Parenchyma length & 197.62 & 57.55 & 259.56 & 58.09 \\
Parenchyma width & 173.44 & 19.80 & 107.44 & 18.79 \\
\hline
\end{tabular}

Table 2. Anatomical characteristics of sun and shade leaves of L. sylvatica collected in the ArctoAlpine tundra (the Jeseníky Mts., Czech Republic). 


\section{Pigment content}

Since total Chl content was more than 3 times higher in sun compared to shade leaves of $L$. sylvatica, the species might be considered as having high plasticity and capacity to acclimate its chloroplastic apparatus to both high and low light environments.

High Car content found in shade leaves (about two times higher than in sun leaves) seems to be unexpected since, typically, high light-grown plants have higher Car content than those grown in low light (see Demmig-Adams and Adams III (1992), for review). However, the ratio of $\mathrm{Car}$ to $\mathrm{Chl}$ reflects the acclimatory changes of photosynthetic pigments to light regime sensitively. The Car/Chl $l_{\text {tot }}$ was found higher for sun than shade leaves (Table 3). The high Car contents provides effective antioxidative activity in chloroplastic apparatus since high light leads to overenergization of PSII and consequtive ROS formation more frequently in sun than shade leaves. High Car contents in high light-grown leaves, however, is not universal because higher Car content in low light-grown than high light-grown leaves is reported as well (Wu et al. 2018). For shade leaves of L. sylvatica, a higher $\mathrm{Chl}_{\mathrm{a}+\mathrm{b}}$ and Car content on a dry matter basis was found and lower weight ratio $\mathrm{Car} / \mathrm{Chl}_{\mathrm{a}+\mathrm{b}}$. This was well comparable to general evidence for sun and shade leaves reported by Lichtenthaler et al. (2007), and Sarijeva et al. (2007).

\begin{tabular}{lcc}
\hline \multicolumn{1}{c}{$\mathrm{mg} \mathrm{g}^{-1} \mathrm{DW}$} & $\begin{array}{c}\text { Sun leaves } \\
\text { Mean } \pm \mathrm{SD}\end{array}$ & $\begin{array}{c}\text { Shade leaves } \\
\text { Mean } \pm \mathrm{SD}\end{array}$ \\
\hline $\mathrm{Chl} a$ & $1.378 \pm 0.131$ & $4.247 \pm 1.378$ \\
$\mathrm{Chl} b$ & $0.501 \pm 0.082$ & $1.598 \pm 0.561$ \\
$\mathrm{Chl} \mathrm{a}+\mathrm{b}\left(\mathrm{Chl}_{\mathrm{tot}}\right)$ & $1.879 \pm 0.211$ & $5.925 \pm 1.795$ \\
$\mathrm{Chl} \mathrm{a} / \mathrm{b}$ (no unit) & $2.781 \pm 0.215$ & $2.713 \pm 0.189$ \\
$\mathrm{Car}$ & $0.449 \pm 0.071$ & $0.949 \pm 0.309$ \\
$\mathrm{Car} / \mathrm{Chl}_{\text {tot }}$ (no unit) & $0.044 \pm 0.008$ & $0.038 \pm 0.004$ \\
\hline
\end{tabular}

Table 3. Photosynthetic pigments contents and ratios in sun and shade leaves of L. sylvatica.

\section{$S P A D$}

The nonlinear relationships between $\mathrm{Chl}_{\mathrm{a}+\mathrm{b}}$ content and SPAD values was obtained for pooled samples of L. sylvatica leaves (Fig. 5). The curvilinear relationship is due to a nonuniform distribution of $\mathrm{Chl}$ across the leaf cateogories (sun, shade, intermediate) and high light scattering causing deviations from linearity at high and low SPAD values. In our study, nonlinear regression was successfully used for estimating $\mathrm{Chl}_{\mathrm{a}+\mathrm{b}}$ contents from SPAD measurements. We found a high non-linear cor- relation between SPAD and $\mathrm{Chl}_{\mathrm{a}+\mathrm{b}}$ content $(\mathrm{R}=0.866$, Fig. 5) comparable to the relationships found for other species, such as e.g. Eugenia uniflora (Mielke et al. 2010). However, linear SPAD to $\mathrm{Chl}_{\mathrm{a}+\mathrm{b}}$ relation is reported as well in some species (Lin et al. 2010). The nonlinear relationship between $\mathrm{Chl}_{\mathrm{a}+\mathrm{b}}$ content and SPAD values (Fig. 5) is attributed to a nonuniform distribution of $\mathrm{Chl}$ across the leaf cateogories (sun, shade, intermediate). Typically, shade leaves had SPAD values higher than 36 , however, 
even lower values were recorded sporadically thanks to sunfleck effects. Seasonal changes in $\mathrm{Chl}_{\mathrm{a}+\mathrm{b}}$ content must be taken into consideration as well. It has been shown that SPAD can monitor seasonal changes in total chlorophyll content, there- fore SPAD values tend to decline towards the end of vegetation season (Caudle et al. 2014). In grasses, SPAD values relate to nitrogen fertilization as shown for e.g. Lolium arundinaceum by Errecart et al. (2012).

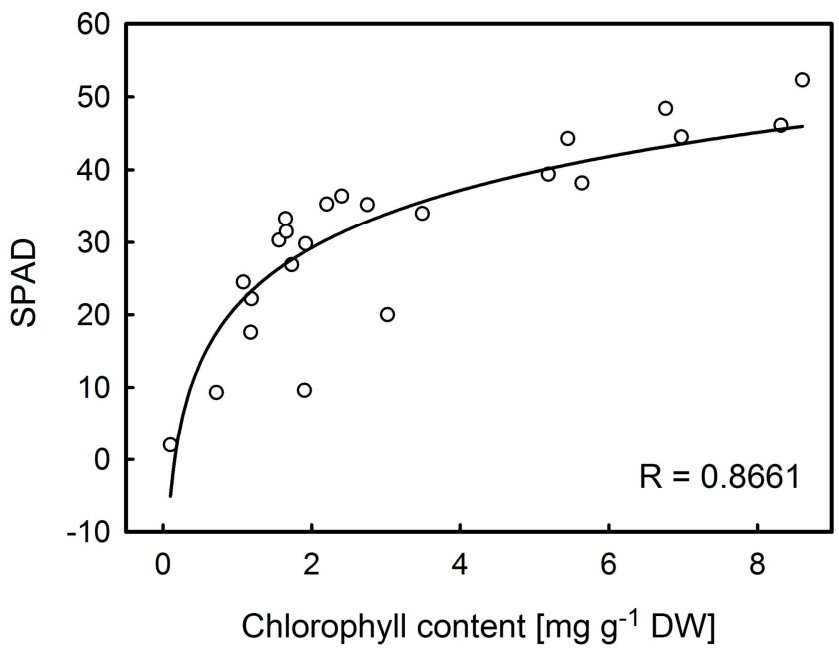

Fig. 5. Relationship between SPAD number (independent variable) and total chlorophyll contents $\left(\mathrm{Ch}_{\mathrm{a}+\mathrm{b}}\right.$, dependent variable, $\left.\mathrm{mg} \mathrm{g}^{-1} \mathrm{DW}\right)$ for all leaf categories.

\section{Reflectance spectra of sun and shade leaves}

Spectral reflectance within the ranges of 380-800 nm was measured in situ by a PolyPen RP 400 (Photon Systems Instruments, Brno, Czech Republic). For measuring the reflectance spectra, leaves were placed into a clip of PolyPen measuring head and then measured after a short darkening period ( $\sim 1 \mathrm{~min}$.). For each leaf category (sun and shade) at least 20 measurements were taken and averaged. The averaged spectral curves were compared between sun and shade leaves (Fig. 6).

\section{Absorption spectra $U V$-B absorbing compounds}

Comparison of absorption specra of sun and shade leaves of L. sylvatica revealed higher contents of UV-absorbing compounds in sun than shade leaves. The difference was apparent in the wavelength range of 210-360 $\mathrm{nm}$ (see the difference spectrum in Fig. 6). The amount of UVabsorbing compounds evaluated according to the Newsham (2003) reached the value of $\mathrm{AUC}_{280-315}$ of $143.5 \pm 30$ for sun leaves, and $109.9 \pm 15$ for shade leaves. 


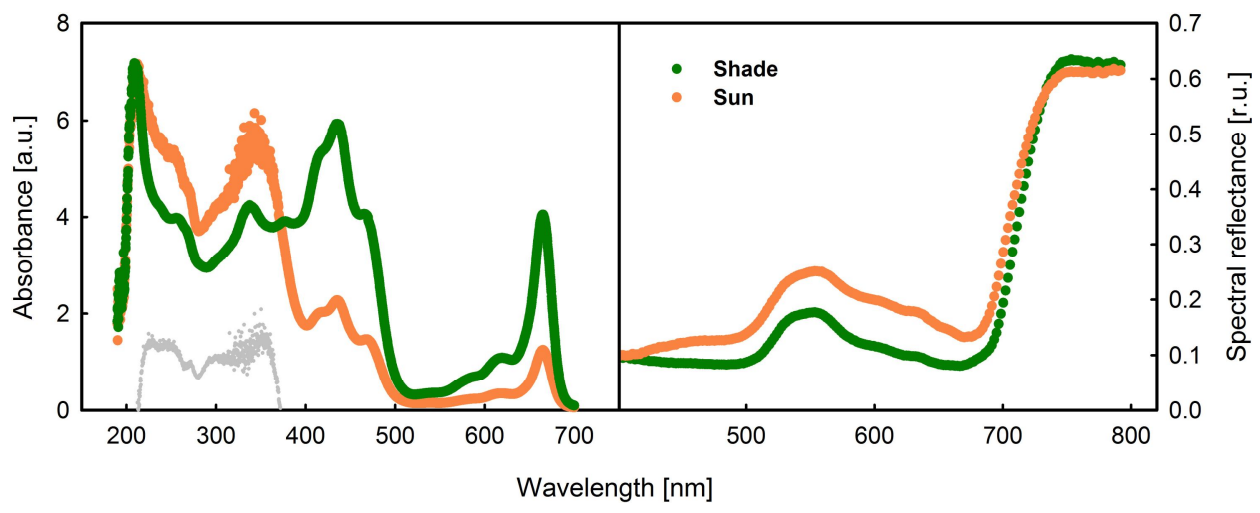

Fig. 6. Left panel - Absorbance spectra of ethanol extracts of L. sylvatica for sun (orange line) and shade (green line) leaves. For the difference in UV-absorbing part of the spectrum, see the differential spectrum - grey. Right panel - spectral reflectance spectra for sun (orange) and shade (green) leaves of $L$. sylvatica.

\section{HPLC-DAD analysis of phenolic compounds}

The HPLC analysis of L. sylvatica leaf extracts revealed wide variety of UV-absorbing phenolic compounds (see peaks in chromatograms detected at $360 \mathrm{~nm}$; Fig. 7). Based on their absorption spectra (Fig. 8), they can be attributed to B-di-hydroxylated and B-mono-hydroxylated flavonoids (mainly luteolin and apigenin derivatives). The presence of luteolin was confirmed by comparing absorption spectrum and retention time with commercially available standard. Further identification without using advanced spectroscopy techniques or proper standard compounds was not possible, however preliminary mass spectrometry analysis (data not shown) confirmed the presence of luteolin (peak 10) and also suggested the presence of luteolin-glucoside (peak 4), and luteolin-methyl-glucoside (peak 2).

The metabolic profile of UV-absorbing compounds in samples from Shade, Spot 1, and Spot 2 sites differed dramatically. One-way ANOVA confirmed significant effect of site on the content of all major compounds; p-values ranged from 0.0362 to $>0.0001$. The total flavonoid content assessed by the sum of peak areas detected at
$360 \mathrm{~nm}$ was markedly lower in Shade samples compared to Spot 1 and 2 (21.8\% of Spot 1, 13.1\% of Spot 2 content; see Fig. 3). In accordance, the content of each individual UV-absorbing compound was the lowest in Shade samples compared to the Spot 1 and 2 (except peaks 3, 4, 8, 9, which content were not significantly different from Spot 1). Further, the relative abundance of individual phenolic compounds varied amongst sites. For instance, in Shade and Spot 1 samples the peaks 7 and 10 exhibited the highest peak areas amongst all peaks within the group, in Spot 2 was the highest value observed for peak 4 (luteolin-glucoside) and peak 10 (luteolin). Spot 2 samples contained the highest amounts of soluble flavonoids, especially of luteolin and peaks $3,4,8,9$, the other compounds exhibited approximately same content as observed in spot 1 . The only exception is peak 6 , which was in general of very low abundance in all samples. The variations of individual UV-B absorbing compounds content amongst all samples is summarized in Suppl. Fig. 1 in a form of heat-maps. 


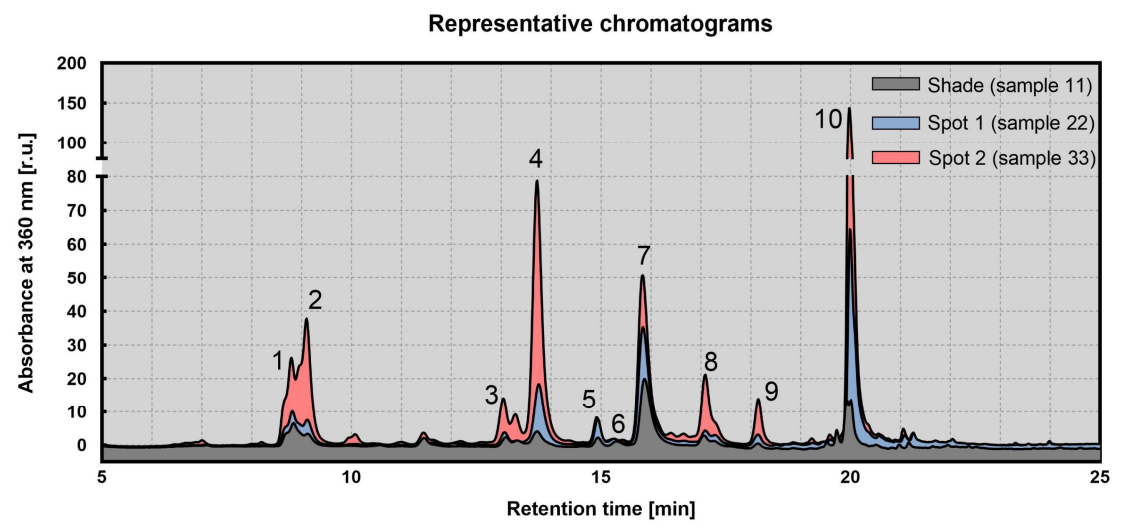

Fig. 7. Representative chromatograms (detected at $360 \mathrm{~nm}$ ) of methanol extracts obtained from L. sylvatica (grey - shade leaves; blue - Spot 1, intermediate leaves; red - Spot 2, sun leaves). The chemical profile of extracted phenolic compounds differed not only in quantity (Shade $<$ Spot 1 $<$ Spot 2) but also in the ratios amongst individual phenolic compound in samples (compare e.g. peaks 4 a 10 in Shade and Spot 2 sample). Identification: luteolin-methyl-glucoside (peak 2), luteolin-glucoside (peak 4), luteolin (peak 10).

A.

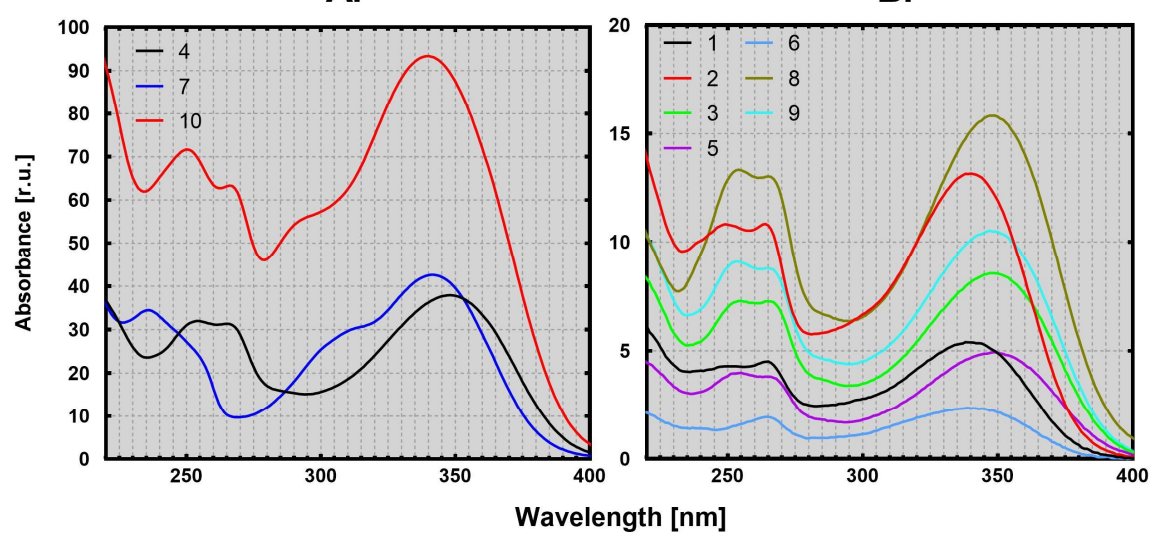

Fig. 8. Absorption spectra belonging to the three most abundant UV-absorbing compound detected in L. sylvatica leaf extracts (A.), and absorption spectra of less abundant compounds (B.) Spectra are numbered according elution order of peaks (see Fig. 7).

HPLC analysis led to effective separation of $10 \mathrm{UV}$-absorbing compounds and allowed their subsequent relative quantification. Whe have tentatively identified/ classified 2 compounds luteolin-mehylglucoside (peak 2) and luteolin-glucoside (peak 4) so far. One of the most abundant flavonoid - luteolin was identified using the corresponding comercially avalible stan- dard (Extrasynthése, France). The luteolin (peak 10) was confirmed by using corresponding comercially available standard (Extrasynthése, France). It is well comparable to the analytical evidence of earier studies in L. sylvatica (Williams and Harborne 1975) and the species of Juncaceae family (Tóth et al. 2017). 


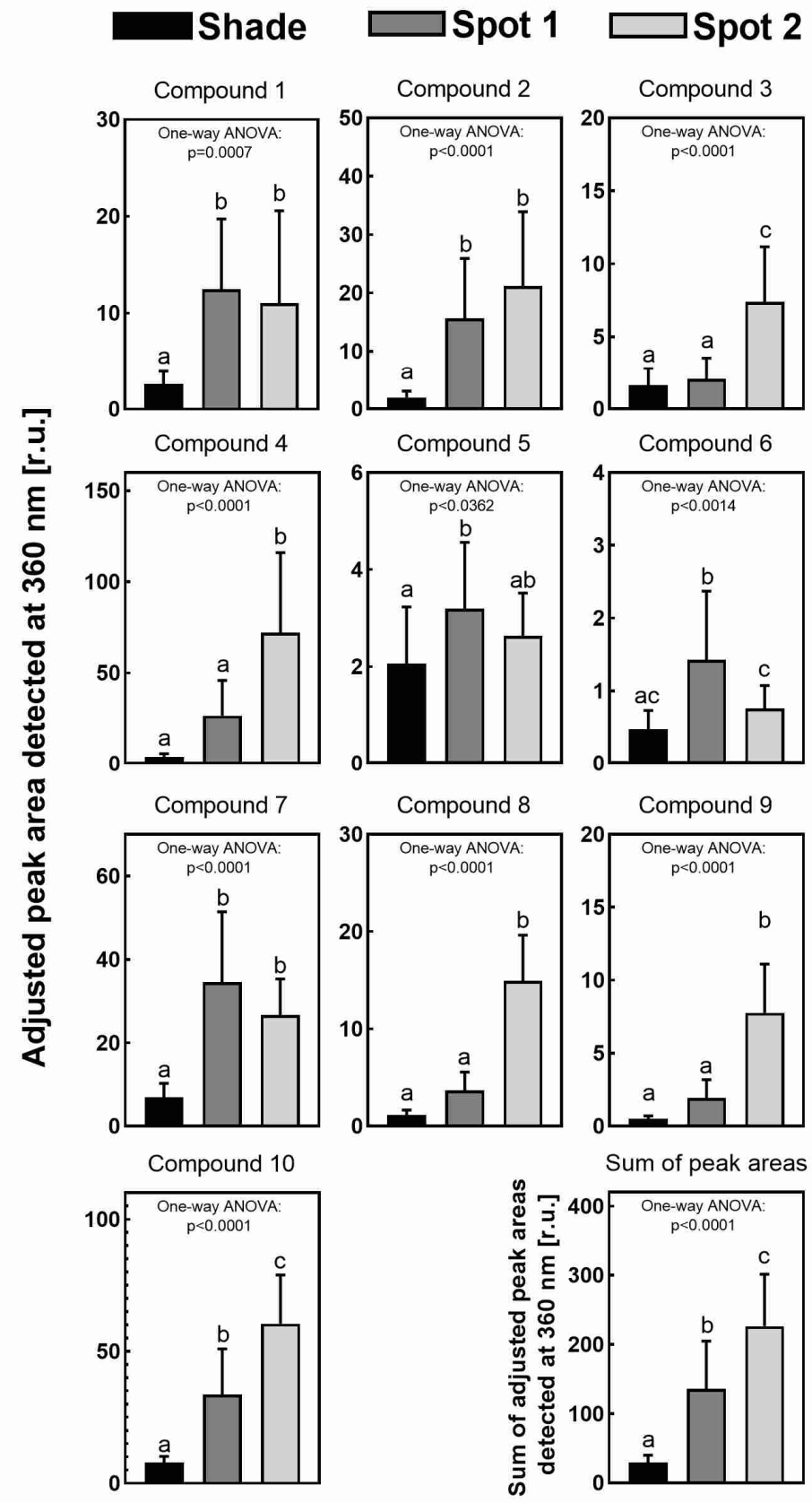

Fig. 9. The relative quantification of UV-absorbing compounds detected in leaf extracts of Luzula sylvatica plants growing at three different sites (Shade - black columns, Spot 1 - dark grey columns, Spot 2 - light grey columns). The assessment of total flavonoid content based on the sum of peak areas is shown (bottom-right sub-figure). The effect of site on the relative content of compounds was tested using one-way ANOVA followed by Tukey's post-hoc test. 
The increase in the above-specified compounds in sun leaves of $L$. sylvatica (Fig. 9) may be attributed to the exposition to UV-B radiation in open, sunny habitat. It is well established that UV-B radiation induces the biosynthesis of some flavonoids, highly effective antioxidants (Agati et al. 2011). The content of phenolic compounds can be effectively increased also by the action of PAR. Synthesis of luteolin-glucoside might be altered by combined UV-B and heat stress (Dias et al. 2019). The other compounds will be identified in a follow-up studies when their standards will be available.

Data presented in Fig. 9 suggest that amount the UV-B screening compounds (numbered 1 to 10 ) is much higher in sun leaves (Spot 1=partly sunny plants Spot

\section{Determination of antioxidant activity}

The antioxidant activity measured in Luzula sylvatica leaf extracts using DPPH• exhibited clear trend similar to the content of soluble phenolic compounds i.e. increase in order Shade $<$ Spot $1<$ Spot 2 (Fig. 10). It was approximately $2 \mathrm{x}$ and $2.6 \mathrm{x}$ higher in the Spot 1 and 2, respectively, compared to Shade. The effect of site on antioxidant activity was confirmed by one-way ANOVA $(\mathrm{p}<0.0001 ; \mathrm{n}=10)$ and differences amongst individual sites by Tukey's post-test. At least a part of the observed antioxidant activity could be related to significantly higher content of luteolin and its derivatives in the Spot1 and the Spot 2 samples.
$2=$ sunny plants in Fig. 9) than shade leaves. All these substances effectively absorb UV-A (chromatograms are detected at $360 \mathrm{~nm}$ - Fig. 8). While the concentration of some UV absorbing substances was about $10 \%$ higher, for others the difference was even 100-1000\% higher, when comparing shade and fully sunny plants of L. sylvatica. It might be, therefore, concluded that plants from different light regimen had in fact substantially different metabolic profile. Antioxidative activities of extracts reached higher values for sun than shade leaves (see Fig. 10, and the information below), which was expected because of high contents of phenolic substances especially of luteolin-based derivative in sun leaves.

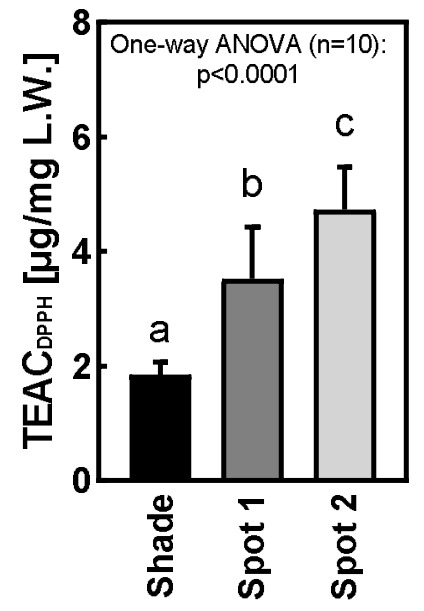

Fig. 10. Antioxidant activity of $L$. sylvatica leaf extracts measured spectrophotometrically using $\mathrm{DPPH} \bullet$ reagent and expressed as TEAC (Trolox Equivalent Antioxidant Capacity) per $\mathrm{mg}$ of lyophilised weight of the sample. Leaf categories: Shade - shade leaves (black column), Spot 1 - intermediate leaves (grey column), Spot 2 - sun leaves of $L$. sylvatica (light grey column). Error bars represent standard deviations. Different letters indicate statistically-significant differences at $\mathrm{P}<0.0001$. 

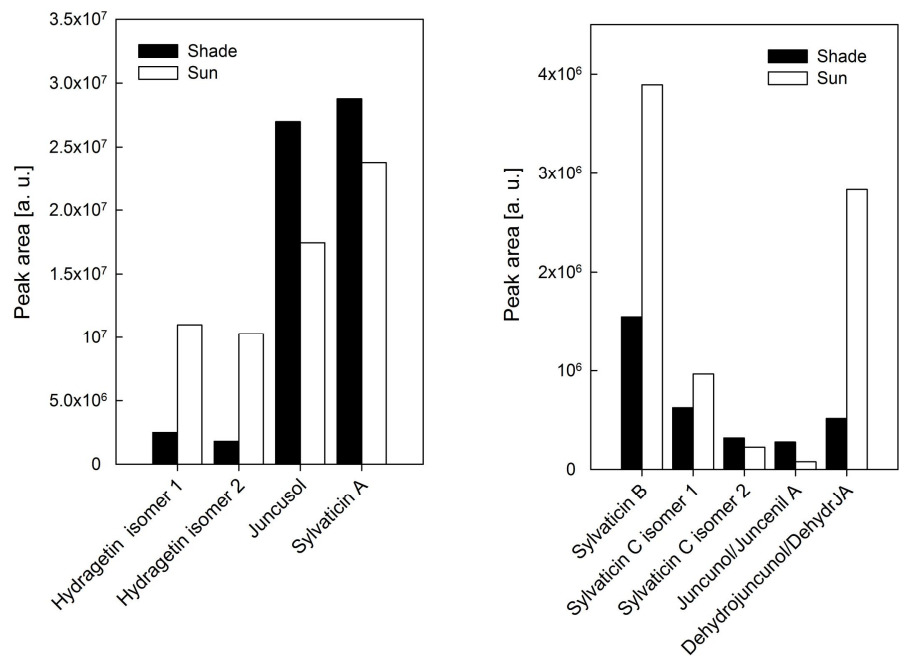

Fig. 11. Phenanthrenoid compounds content in shade (black bars) and sun leaves from Spot 2 (white bars) of $L$. sylvatica collected in late autumn season 2020. Standard deviations are so small that they are hardly visible.

Nine phenanthrenoids were identified in the extracts from leaves of L. sylvatica. Their content showed a great difference between sun and shade leaves. Higher contents of five phenanthrenoids (hydragetin isomer 1, hydragetin isomer 2, Sylvaticin $\mathrm{B}$, Sylvaticin C isomer 1, and Dehydrojuncunol/Dehydr. JA) were found in sun than shade leaves. Lower contents of Juncusol, Sylvaticin A, Sylvaticin C isomer 2, and Juncunol/Juncenil A were found in sun compared to shade leaves. Phenanthrenoid substances are reported from the plants of Juncaceae family (Tóth 2017) and L. sylvatica specifically (Gainche et al. 2020). In these studies leaf type and category have not been taken into consideration. We suggest that follow-up studies should focus the effect of prevailing light regimen and ecophysiological factors on phenanthreoids contents in leaf. Moreover, our data (not shown here) suggest also the seasonal effect on phenathreoids synthesis and content in a leaf.

\section{References}

Agati, G., Biricolti, S., Guidi, L., Ferrini, F., Fini, A. and Tattini, M. (2011): The biosynthesis of flavonoids is enhanced similarly by UV radiation and root zone salinity in $L$. vulgare leaves. Journal of Plant Physiology, 168: 204-212.

CAudle, K. L., Johnson, L. C., BAER, S. G. and Maricle, B. B. (2014): A comparison of seasonal foliar chlorophyll change among ecotypes and cultivars of Andropogon gerardii (Poaceae) by using nondestructive and destructive methods. Photosynthetica, 52 (4): 511-518.

Dias, M. C., Figueiredo, C., Pinto, D. C. G. A., Freitas, H., Santos, C. and Silva, A. M. S. (2019): Heat shock and UV-B episodes modulate olive leaves lipophilic and phenolic metabolite profiles. Industrial Crops and Products, 133: 269-275.

Demmig-ADAms, B., ADAMs, W. W. III (1992): Carotenoid composition in sun and shade leaves of plants with different life forms. Plant Cell and Environment, 15: 411-419

Dong, T., Shang, J., Chen, J. M., Liu, J., Qian, B., Ma, B., Morrison, M. J., Zhang, C., Liu, Y., SHI, Y., PAN, H. and ZHOU, G. (2019): Assessment of portable chlorophyll meters for measuring crop leaf chlorophyll concentration. Remote Sensing, 11(22): 2706. 
Errecart, P. M., Agnusdei, M. G., Lattanzi, F. A. and Marino, M. A. (2012): Leaf nitrogen concentration and chlorophyll meter readings as predictors of tall fescue nitrogen nutrition status. Field Crops Research, 129: 46-58.

GÁBORČ́́, N. (2003): Relationship between contents of chlorophyll $(a+b)($ SPAD values) and nitrogen of some temperate grasses. Photosynthetica, 41 (2): 285-287.

Gainche, M., Ripoche, I., Senejoux, F., Cholet, J., Ogeron, C., Decombat, C., Danton, O., Delort, L., Vareille-Delarbre, M., Berry, A., Vermerie, M., Fraisse, D., Felgines, C., Ranouille, E., Berthon, J.-Y., Priam, J., Saunier, E., Tourrette, A., Troin, Y., CaldefieChezet, F. and Chalard, P. (2020): Anti-inflammatory and cytotoxic potential of new phenanthrenoids from Luzula sylvatica. Molecules, 25: 2372. doi:10.3390/molecules25102372.

Holub, P., Klem, K., Linder, S. and Urban, O. (2019): Distinct seasonal dynamics of responses to elevated $\mathrm{CO}_{2}$ in two understorey grass species differing in shade tolerance. Ecology and Evolution, 9: 13663-13677.

HuANG, W., ZHANG, S.-B. and Hu, H. (2014): Sun leaves up-regulate the photorespiratory path way to maintain a high rate of $\mathrm{CO}_{2}$ assimilation in tobacco. Frontiers in Plant Science, 5: 688.

KuČera, J., Zmrhalová, M., Shaw, B., Košnar, J., PlášEK, V. and VÁŇA, J. (2009): Bryoflora of selected localities of the Hrubý Jeseník Mts summit regions. Časopis Slezské zemské muzeum (A), 58: 115-167.

KŘižze, M., Krause, D., Uxa, T., Engel, Z., Treml, V. and Traczyk, A. (2019): Patterned ground above the alpine timberline in the High Sudetes, Central Europe. Journal of Maps, 15: 563-569.

Lichtenthaler, H. K., AČ, A., Marek, M. V., Kalina, J. and Urban, O. (2007): Differences in pigment composition, photosynthetic rates and chlorophyll fluorescence images of sun and shade leaves of four tree species. Plant Physiology and Biochemistry, 45(8): 577-588.

Lin, F. F., QIU, L. F., DenG, J. S., SHI, Y. Y., ChEN, L. S. and WANG, K. (2010): Investigation of SPAD meter-based indices for estimating rice nitrogen status. Computers and Electronics in Agriculture, 715: 560-565.

Markwell, J., Osterman, J. C. and Mitchell, J. L. (1995): Calibration of the Minolta SPAD-502 leaf chlorophyll meter. Photosynthesis Research, 46: 467-472.

Mathur, S., Jain, L. and JaJOO, A. (2018): Photosynthetic efficiency in sun and shade plants. Photosynthetica, 56(1): 354-365.

MielKe, M. S., Schaffer, B. and Li, C. (2010): Use of a SPAD meter to estimate chlorophyll content in Eugenia uniflora L. leaves as affected by contrasting light environments and soil flooding. Photosynthetica, 48(3): 332-338.

Lichtenthaler, H. K., Wellburn, A. R. (1983): Determinations of total carotenoids and chlorophyllsaandbof leafextracts in different solvents. Biochemical Society Transactions, 11: 591-592.

Netto, A. T., Campostrini, E., De Oliveira, Gonçalves, J., Bressan-Smith, R. E. (2005): Photosynthetic pigments, nitrogen, chlorophyll a fluorescence and SPAD-502 readings in coffee leaves. Scientia Horticulturae, 104: 199-209.

NEwSHAM, K. K. (2003): UV-B radiation arising from stratospheric ozone depletion influences the pigmentation of the Antarctic moss Andreaea regularis. Oecologia, 135: 327-331.

Pandey, S., Kushwaha, R. (2005): Leaf anatomy and photosynthetic acclimation in Valeriana jatamansi L. grown under high and low irradiance. Photosynthetica, 43(1): 85-90.

PARry, C,. J. Blonquist, J. M. JR., BugBeE B. (2014): In situ measurement of leaf chlorophyll concentration: analysis of the optical/absolute relationship. Plant, Cell and Environment, 37: 2508-2520.

SariJeVA, G., Knapp, M. and Lichtenthaler, H. K., (2007): Differences in photosynthetic activity, chlorophyll and carotenoid levels, and in chlorophyll fluorescence parameters in green sun and shade leaves of Ginkgo and Fagus. Journal of Plant Physiology, 164: 950-955.

ŠEnFELDR, M., TREML, V. (2020): Which generative reproduction characteristics determine successful establishment of subalpine dwarf shrub Pinus mugo? Journal of Vegetation Science, 31: 403-415. 
Terashima, I., Miyazawa, S.-I. and Hanba Y. T. (2001): Why are Sun Leaves Thicker than Shade Leaves? Consideration based on Analyses of $\mathrm{CO}_{2}$, Diffusion in the Leaf. Journal of Plant Research, 114: 93-105.

Tóth, B., Chang, F.-R., Hwang, T.-L., Szappanos, Á., Mándi, A., Hunyadi, A., Kurtán, T., JAKAB, G., Hohmann, J. AND VASAS, A. (2017): Screening of Luzula species native to the Carpathian Basin for anti-inflammatory activity and bioactivity-guided isolation of compounds from Luzula luzuloides (Lam.) Dandy \& Wilmott. Fitoterapia, 116: 131-138.

Udding, J., Gelang-Alfredsson, J., PiikKi, K. and PleiJel, H. (2007): Evaluating the relationship between leaf chlorophyll concentration and SPAD-502 chlorophyll meter readings. Photosynthesis Research, 91: 37-46.

Williams, C. A., HARBorne, J. B. (1975): Luteolin and daphnetin derivatives in the Juncaceae and their systematic signifikance. Biochemical Systematics and Ecology, 3: 181-190.

Wu, J. W., Su, Y., WANG, J. H., He, Q., QIU, Q., MA, J. W. and LI, J. Y. (2018): Morphological and physiological acclimation of Catalpa bungei plantlets to different light conditions Photosynthetica, 56(2): 537-548.

Xiong, D., Chen, J., Tingting, Y., GaO, W., Ling, X., Li, Y., Shaobing P. and Huang, J. (2015): SPAD-based leaf nitrogen estimation is impacted by environmental factors and crop leaf characteristics. Scientific Reports, 5(1): 13389.

Ziedler, M., DuchoslaV, M., Banaš, M. and LeŠKovÁ, M. (2012): Impacts of introduced dwarf pine (Pinus mugo) on the diversity and composition of alpine vegetation. Community Ecology, 13: $213-220$.

Ziedler, M., Hertlová, B., BANAŠ, M. and Zahradník, D. (2018): Vegetation shift after a clearcut of non-native dwarf pine (Pinus mugo). Biologia, 73: 113-119.

\section{Web sources / Other sources}

[1] Public weather data for Praděd, the Jeseniky mountains (non-commertial use), www.meteoblue.com (Meteoblue AG, Basel, Switzerland)

A.

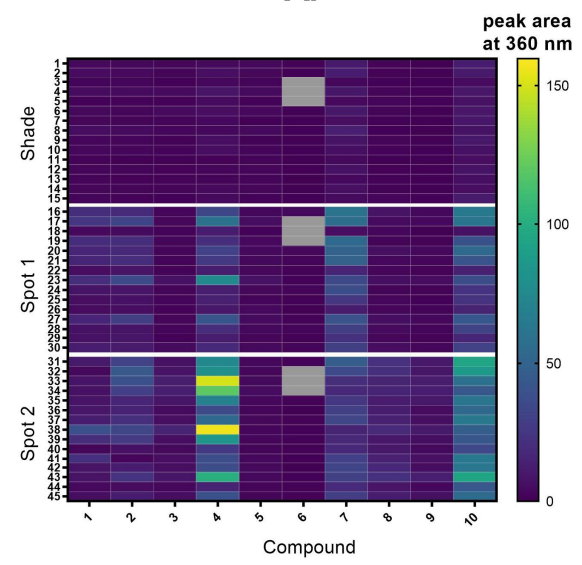

B.

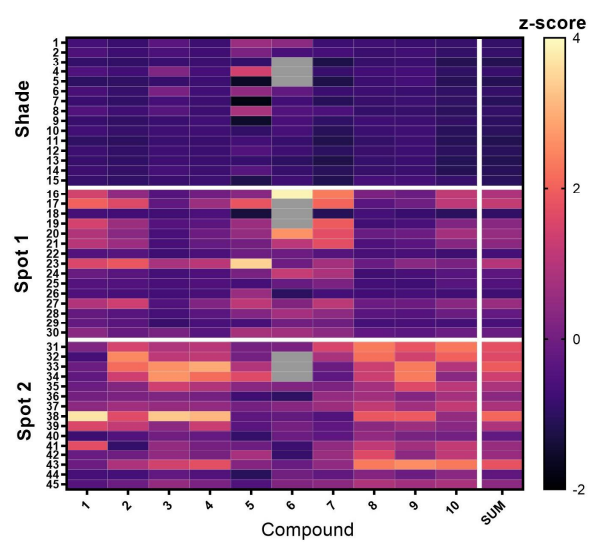

Supplementary Fig. 1. Upper panel: An overview of UV-absorbing compound variability amongst observed samples and leaf category (shade, sun-Spot1, sun-Spot2), the pseudo-colouring express the peak areas detected in samples adjusted to L.W.; Lower panel: Same data set as in the left subpanel with applied $\mathrm{z}$-score transformation i.e. resulting value $=$ (observed valuemean)/SD, the pseudo-coloring better indicates relative differences amongst sample and treatments regardless on total quantity of the compound; grey cells - peak was not detectable in the sample. 